\title{
Review: changing (shared) heritability of ASD and ADHD across the lifespan
}

\author{
Nanda N. J. Rommelse ${ }^{1,2}$ - Catharina A. Hartman ${ }^{3}$
}

Published online: 16 February 2016

(C) Springer-Verlag Berlin Heidelberg 2016

\section{Introduction}

Autism spectrum disorder (ASD) and attention-deficit/ hyperactivity disorder (ADHD) frequently co-occur. In clinical practice, we daily struggle deciding if one, or the other, or both disorders, best describe the child's problems. A strong body of literature has convincingly shown that large overlap exists regarding genetic factors $[6,11$, 26, 29]. However, this genetic overlap may significantly depend on age. It is well known that genetic influences on behavior are not at all constant during development and continuously co-act and interact with environmental factors influencing behavioral functioning [1, 30]. For example, increasing heritability can result from amplification, whereby early genetic influences become stronger across time. As a second example, genetic influences may be stable; yet novel genetic influences may emerge with time while early genetic influences may decrease [2]. Despite everyone's awareness of change in the (genetic) mechanisms underlying the development of an individual until elderly age in typical development, studies on neurodevelopmental disorders like ADHD and ASD have

Nanda N. J. Rommelse

Nanda.Lambregts-Rommelse@ radboudumc.nl

1 Department of Psychiatry, Donders Institute for Brain, Cognition and Behavior, Radboud University Medical Center, Nijmegen, The Netherlands

2 Karakter, Child and Adolescent Psychiatry University Center, Nijmegen, The Netherlands

3 Department of Psychiatry, Interdisciplinary Center of Psychopathology and Emotion Regulation (ICPE) and Research School of Behavioral and Cognitive Neuroscience, University of Groningen, University Medical Center Groningen, Groningen, The Netherlands been strongly focused on childhood. The age of onset for ASD and ADHD is nearly always in childhood ([18]; but see [17]), which is the likely reason for this bias. However, given that it is already well known that developmental changes take place in both ADHD and ASD symptom domains separately, a focus beyond childhood is needed to further understand the potentially changing etiology of ADHD-ASD co-occurrence.

\section{Heritability of ADHD across the lifespan}

Several longitudinal twin studies on ADHD symptoms report that new, age-specific genetic effects influence ADHD symptoms in adolescence and adulthood, suggesting that ADHD symptoms are a developmentally complex phenotype characterized by both continuity and change across the life span [3, $9,12,13,19]$. In addition, only a modest overlap between longitudinal genetic effects underlying both symptom domains (inattention versus hyperactivity/impulsivity) appears present, suggesting it is necessary to study both separately. Moreover, several longitudinal studies report that subgroups may be formed based on various combinations of symptoms in both domains across the longitudinal course that likely has partly distinct genetic underpinnings ([7, 14, 25]). These findings strongly suggest that genetic effects implicated in childhood ADHD may not at all be directly comparable to those that influence ADHD in adulthood. This concurs with a review on molecular genetics in adult ADHD, where it was concluded that only some genes potentially related to childhood ADHD have been replicated in adults with the disorder [8]. In addition, in some cases the same genes were implicated, but different alleles increased the risk for ADHD in children versus adults (for instance, the 10-repeat in the dopamine transporter gene [DAT1] increased the risk for ADHD in children, but decreased the risk in adults) [8]. Note though that currently 
there are no unequivocal molecular genetic findings for ADHD in either childhood or adulthood, possibly contributing to these results. Moffitt et al. [17] reported about adults aged 38 years presenting with an ADHD symptom picture, who did not have childhood ADHD as assessed in early adolescence. They did not share the genetic and neuropsychological alterations of those who did have the childhood diagnosis. Even during adolescence, environmental effects (like smoking) controlled for genetic confounders may have a significant impact on future development of ADHD symptoms [33], illustrating the developmentally sensitive nature and non-static genetic influence of the ADHD phenotype beyond childhood.

\section{Heritability of ASD across the life span}

In comparison to ADHD, fewer longitudinal, genetically informative studies have examined the developmental nature of ASD symptoms into adolescence or even adulthood. Specifically, studies on the presence of new genetic effects occurring in late adolescence or adulthood compared to childhood-as reported for ADHD-have not yet been conducted. In addition, to what extent the different symptom domains of ASD are influenced by distinct genetic effects over time is unknown. A study reporting on the stability of genetic effects from childhood into early adolescence (12 years) reported that ASD traits were stable and there was a high degree of overlap in genetic influences across age, with shared environmental factors playing virtually no role [10]. In a small male sample of twin pairs and affected singletons (including adolescents), developmentally stable and strongly genetically determined social responsivity problems were found [4].

\section{Shared heritability of ASD and ADHD across the lifespan}

Twin studies suggest that the genetic mechanisms underlying the co-occurrence of ASD and ADHD traits may vary with age and depend on symptom domain. Low genetic correlations (0.27) between ASD and ADHD traits have been reported in 2-year-olds [27], whereas stronger genetic correlations $(\sim 0.40-0.60)$ have been reported in childhood age twin samples $[5,16,20,23,28]$. This contrast with the high genetic correlation (0.87) between ASD and ADHD in a sample of young adolescents (12 years old) [15], albeit findings in a similar age group suggest genetic correlations may be symptom domain specific [moderately strong between communication difficulties and traits of ADHD ( 0.50), but low to moderate for other ASD domains $(\sim 0.05-0.30)][31,32]$. A sample of late adolescent/young adults (18-33 years) showed a moderately strong genetic correlation $(\sim 0.70)$ between ASD and ADHD traits [24], albeit studies including a similar age range found lower genetic correlations $(\sim 0.20-0.60)$, strongest between repetitive behaviors and ADHD symptoms ([21]; see also [16]). A study including two elderly adult samples (mean age $\sim 45$ years, maximum $\sim 75$ years) revealed a prominent genetic correlation between attention problems (ADHD inattention scale and the ASD attentional switching scale) (0.80) [22]. The only longitudinal twin study mapping both ASD and ADHD traits has been conducted in children ( 8 years) followed into early adolescence (12 years) suggested that there was a somewhat stronger (but still modest) shared genetic load for ADHD and ASD overlap at age 8 years ( $\sim .30)$ than at age $12(\sim 0.10)$ [31]. These studies demonstrate heterogeneity in the genetic overlap between ASD and ADHD and illustrate the dynamic nature of co-occurring ASD/ADHD traits across development.

\section{Summary and conclusion}

In summary, ADHD and ASD symptoms are developmentally complex phenotypes characterized by both continuity and change across the lifespan. Genetic factors co-act and interact continuously throughout the lifespan with environmental factors influencing behavioral functioning. Longitudinal twin studies on ADHD symptoms report that new, age-specific genetic effects influence both ADHD symptom domains in adolescence and adulthood. It is plausible that this holds for ASD as well, although there are currently no data to confirm this. However, all these findings pertain to heritability estimates based on statistical genetic studies (mostly twin studies). An elucidation of the relevance of identified gene variants over the age span rests on molecular genetic studies with patients followed over the lifespan. Molecular genetic studies on ADHD and ASD are only beginning to take lifespan developmental change into account. Findings on genetic mechanisms underlying ASD and ADHD in childhood years cannot be automatically extrapolated to adolescence and adulthood. Even after childhood onset, other crucial developmental phases may exist, wherein new genetic effects could become relevant in determining further development of these disorders. Therefore, a full understanding of the mechanisms behind ADHD-ASD co-occurrence requires a lifespan approach-in contrast to the current practice to focus on the childhood years.

\section{References}

1. Bergen SE, Gardner CO, Kendler KS (2007) Age-related changes in heritability of behavioral phenotypes over adolescence and young adulthood: a meta-analysis. Twin Res Hum Genet 10:423-433

2. Briley DA, Tucker-Drob EM (2013) Explaining the increasing heritability of cognitive ability across development: a 
meta-analysis of longitudinal twin and adoption studies. Psychol Sci 24:1704-1713

3. Chang Z, Lichtenstein P, Asherson PJ, Larsson H (2013) Developmental twin study of attention problems: high heritabilities throughout development. JAMA Psychiatry 70(3):311-318

4. Constantino JN, Abbacchi AM, Lavesser PD, Reed H, Givens L, Chiang L, Gray T, Gross M, Zhang Y, Todd RD (2009) Developmental course of autistic social impairment in males. Dev Psychopathol 21(1):127-138

5. Constantino JN, Hudziak JJ, Todd RD (2003) Deficits in reciprocal social behavior in male twins: evidence for a genetically independent domain of psychopathology. J Am Acad Child Adolesc Psychiatry 2003(42):458-467

6. Doherty JL, Owen MJ (2014) Genomic insights into the overlap between psychiatric disorders: implications for research and clinical practice. Genome Med 2014(6):29

7. Elia J, Arcos-Burgos M, Bolton KL, Ambrosini PJ, Berrettini W, Muenke M (2009) ADHD latent class clusters: DSM-IV subtypes and comorbidity. Psychiatry Res 170(2-3):192-198

8. Franke B, Faraone SV, Asherson P, Buitelaar J, Bau CH, RamosQuiroga JA, Mick E, Grevet EH, Johansson S, Haavik J, Lesch KP, Cormand B, Reif A, International Multicentre persistent ADHD Collaboration (2012) The genetics of attention deficit/hyperactivity disorder in adults, a review. Mol Psychiatry 17(10):960-987

9. Greven CU, Asherson P, Rijsdijk FV, Plomin R (2011) A longitudinal twin study on the association between inattentive and hyperactive-impulsive ADHD symptoms. J Abnorm Child Psychol 39(5):623-632

10. Holmboe K, Rijsdijk FV, Hallett V, Happé F, Plomin R, Ronald A (2014) Strong genetic influences on the stability of autistic traits in childhood. J Am Acad Child Adolesc Psychiatry 53(2):221-230

11. Johnson MH, Gliga T, Jones E, Charman T (2015) Annual research review: infant development, autism, and ADHD — early pathways to emerging disorders. J Child Psychol Psychiatry 56(3):228-247

12. Kan KJ, Dolan CV, Nivard MG, Middeldorp CM, van Beijsterveldt CE, Willemsen G, Boomsma DI (2013) Genetic and environmental stability in attention problems across the lifespan: evidence from the Netherlands twin register. J Am Acad Child Adolesc Psychiatry 52(1):12-25

13. Larsson JO, Larsson H, Lichtenstein P (2004) Genetic and environmental contributions to stability and change of ADHD symptoms between 8 and 13 years of age: a longitudinal twin study. $\mathbf{J}$ Am Acad Child Adolesc Psychiatry 43(10):1267-1275

14. Larsson H, Dilshad R, Lichtenstein P, Barker ED (2011) Developmental trajectories of DSM-IV symptoms of attention-deficit/ hyperactivity disorder: genetic effects, family risk and associated psychopathology. J Child Psychol Psychiatry 52(9):954-963

15. Lichtenstein $\mathrm{P}$, Carlström $\mathrm{E}$, Råstam M, Gillberg C, Anckarsäter H (2010) The genetics of autism spectrum disorders and related neuropsychiatric disorders in childhood. Am J Psychiatry 2010(167):1357-1363

16. Lundström S, Chang Z, Kerekes N, Gumpert $\mathrm{CH}$, Råstam M, Gillberg C, Lichtenstein P, Anckarsäter H (2011) Autistic-like traits and their association with mental health problems in two nationwide twin cohorts of children and adults. Psychol Med 41(11):2423-2433

17. Moffitt TE, Houts R, Asherson P, Belsky DW, Corcoran DL, Hammerle M, Harrington H, Hogan S, Meier MH, Polanczyk GV, Poulton R, Ramrakha S, Sugden K, Williams B, Rohde LA, Caspi A (2015) Is adult ADHD a childhood-onset neurodevelopmental disorder? Evidence from a Four-Decade Longitudinal Cohort Study. Am J Psychiatry 172(10):967-977
18. Mohr Jensen C, Steinhausen HC (2015) Comorbid mental disorders in children and adolescents with attention-deficit/hyperactivity disorder in a large nationwide study. Atten Defic Hyperact Disord 7(1):27-38

19. Pingault JB, Viding E, Galéra C, Greven CU, Zheng Y, Plomin R, Rijsdijk F (2015) Genetic and environmental influences on the developmental course of attention-deficit/hyperactivity disorder symptoms from childhood to adolescence. JAMA Psychiatry 72(7):651-658

20. Pinto R, Rijsdijk F, Ronald A, Asherson P, Kuntsi J (2015) The genetic overlap of attention-deficit/hyperactivity disorder and autistic-like traits: an investigation of individual symptom scales and cognitive markers. J Abnorm Child Psychol (epub ahead of print)

21. Polderman TJ, Hoekstra RA, Posthuma D, Larsson H (2014) The co-occurrence of autistic and ADHD dimensions in adults: an etiological study in 17,770 twins. Transl Psychiatry 2014(4):e435

22. Polderman TJ, Hoekstra RA, Vinkhuyzen AA, Sullivan PF, van der Sluis S, Posthuma D (2013) Attentional switching forms a genetic link between attention problems and autistic traits in adults. Psychol Med 43(9):1985-1996

23. Reiersen AM, Constantino JN, Volk HE, Todd RD (2007) Autistic traits in a population-based ADHD twin sample. J Child Psychol Psychiatry 48(5):464-472

24. Reiersen AM, Constantino JN, Grimmer M, Martin NG, Todd RD (2008) Evidence for shared genetic influences on selfreported ADHD and autistic symptoms in young adult Australian twins. Twin Res Hum Genet 11(6):579-585

25. Robbers SC, van Oort FV, Polderman TJ, Bartels M, Boomsma DI, Verhulst FC, Lubke GH, Huizink AC (2011) Trajectories of CBCL attention problems in childhood. Eur Child Adolesc Psychiatry 20(8):419-427

26. Rommelse NN, Franke B, Geurts H, Hartman CA, Buitelaar JK (2010) Shared heritability of attention-deficit/hyperactivity disorder and autism spectrum disorder. Eur Child Adolesc Psychiatry 19:281-295

27. Ronald A, Edelson L, Asherson P, Saudino K (2010) Exploring the relationship between autistic-like traits and ADHD behaviors in early childhood: findings from a community twin study of 2-year-olds. J Abnorm Child Psychol 38:185-196

28. Ronald A, Happé F, Plomin R (2008) A twin study investigating the genetic and environmental aetiologies of parent, teacher and child ratings of autistic-like traits and their overlap. Eur Child Adolesc Psychiatry 17:473-483

29. Ronald A, Hoekstra RA (2011) Autism spectrum disorders and autistic traits: a decade of new twin studies. Am J Med Gen B $156: 255-274$

30. Rutter M, Moffitt TE, Caspi A (2006) Gene-environment interplay and psychopathology: multiple varieties but real effects. J Child Psychol Psychiatry 47:226-261

31. Taylor MJ, Charman T, Robinson EB, Plomin R, Happé F, Asherson P, Ronald A (2013) Developmental associations between traits of autism spectrum disorder and attention deficit hyperactivity disorder: a genetically informative, longitudinal twin study. Psychol Med 43(8):1735-1746

32. Taylor MJ, Charman T, Ronald A (2015) Where are the strongest associations between autistic traits and traits of ADHD? Evidence from a community-based twin study. Eur Child Adolesc Psychiatry 24(9):1129-1138

33. Treur JL, Willemsen G, Bartels M, Geels LM, van Beek JH, Huppertz C, van Beijsterveldt CE, Boomsma DI, Vink JM (2015) Smoking during adolescence as a risk factor for attention problems. Biol Psychiatry 78(9):656-663 